\title{
Reply to the letter to the editor by Swarthout et al. (2018): Comments for Mertens et al. (2018), Glyphosate, a chelating agent-relevant for ecological risk assessment?
}

\author{
Martha Mertens ${ }^{1}$ (D) $\cdot$ Sebastian Höss ${ }^{1} \cdot$ Günter Neumann ${ }^{2} \cdot$ Joshua Afzal $^{2} \cdot$ Wolfram Reichenbecher $^{3}$
}

Received: 14 May 2018 / Accepted: 28 May 2018 / Published online: 3 June 2018

(C) Springer-Verlag GmbH Germany, part of Springer Nature 2018

In their letter to the editor, Swarthout and colleagues (Swarthout et al. 2018) comment on our publication "Glyphosate, a chelating agent - relevant for ecological risk assessment?" (Mertens et al. 2018), and criticize several issues that we want to refute with this response item by item:

- "Glyphosate was not patented as chelator": In their letter to the editor, Swarthout and colleagues criticize that we may have inadvertently perpetuated a critical piece of misinformation, namely the widely held belief that glyphosate was patented as chelator. They rightly point out that it is not glyphosate itself and other aminomethylenephosphonic acids which have been patented in 1964, but aminomethylenephosphinic acids which serve as chemical intermediates to produce aminomethylenephosphonic acids and derivatives thereof, including glyphosate. The Stauffer Chemical Company patent 3,160,632 (Toy and Uhing 1964) provides examples for the synthesis of both phosphinic acids and derived phosphonic acids including glyphosate. It describes the patented compounds (phosphinic acids) as having a wide variety of uses amongst others as chelating agents and provides data for the chelating power for some phosphinic as well as phosphonic acids, but not for glyphosate, as pointed out by Swarthout et al. (2018).

Responsible editor: Philippe Garrigues

Martha Mertens

mertens@biodiv.de

1 Institute for Biodiversity Network, Nussbergerstr. 6a, 93059 Regensburg, Germany

2 Institute of Crop Science (340h), University of Hohenheim, 70599 Stuttgart, Germany

3 Federal Agency fo Nature Conservation (BfN), Konstantinstr. 110, 53179 Bonn, Germany
Because of this we accept the critique that our statement "Glyphosate is also known as a potent chelator for minerals, a property that has been observed decades ago (Toy and Uhing 1964)" is misleading. We regret this imprecision; however, we don't accept the general accusation that Mertens et al. (2018) relied on secondary sources instead of reading the original papers (Letter to the editor, p.3, 1. 16-18).

- Interaction of glyphosate with nutrients in soil and phloem: The letter to the editor claims: “(...) the basis for this assertion is not substantiated by the facts. This includes that (...) the chelating properties of glyphosate do not support any hypothesis that glyphosate could play a significant role in limiting the bioavailability of micronutrients to plants" (p. 3, 1. 1115). Reviewing the literature, claiming a potential risk of glyphosate-mediated nutrient immobilization (page 5305, Eker et al. 2006; Tesfamariam et al. 2009; Cakmak et al. 2009), Mertens et al. (2018) finally came to the same conclusion proposed by Swarthout and colleagues: "The available data implicate that... a significant direct longterm impact of glyphosate and AMPA on bioavailability of metals in soils seems to be rather unlikely (...)" (see p. 5305). The same holds true for the possibility of internal immobilization of micronutrients by sequestration with glyphosate within plant organs. The only exceptional scenario considered as possible is the preferential accumulation of glyphosate and AMPA in high concentrations in young growing and meristematic tissues of glyphosateresistant plants. Due to a generally low phloem-mobility, there is a high risk of micronutrient limitations in these tissues particularly under conditions of limited micronutrient availability, and the preferential accumulation of high concentrations of glyphosate could further contribute to aggravation of these problems by metal sequestration in the respective tissues. Correspondingly, it reads on page 5309 in Mertens et al. (2018): "These findings suggest that 
internal micronutrient immobilization may be a realistic scenario in GR crops after application of regular glyphosate doses but not for low-level contamination of nontarget crops by herbicide drift or rhizosphere transfer". Since we are not aware of any data on speciation analysis and ligand concentrations in the respective tissues, we recommend additional research and wrote on page 5310 in Mertens et al. (2018): "Nevertheless, testing these hypotheses would require more detailed comparative and localized measurements of both glyphosate/AMPA concentrations and the respective counterions, including speciation analysis in tissues and plant organs showing preferential glyphosate accumulation and, in addition, activity monitoring of metabolic pathways affected by limited micronutrient availability."

Also, we did never state that glyphosate could mediate the sequestration of micronutrients in the phloem. Due to the generally limited role of phloem transport for many micronutrients, this process, also addressed by Harris et al. (2012) using computational speciation analysis, was rather considered as irrelevant and therefore not mentioned at all by Mertens et al. (2018). Our only statement on phloem transport addresses phloem mobility of micronutrients in general: “...due to limited phloem mobility (of micronutrients), young leaves are particularly susceptible for micronutrient deficiencies" (Mertens et al. 2018, p. 5309).

In summary, the claims in the letter to the editor concerning glyphosate effects on plant micronutrient availability are not reflected by the statements of Mertens et al. (2018) and seem to be caused by misinterpretation or misunderstanding.

Duke et al. (2017) field study The letter to the editor refers to the conclusion of Duke et al. (2017) "Neither glyphosate nor the GR transgene affect the content of the minerals measured in leaves and seed, harvested seed amino acid composition, or yield of GR soybean." Mertens et al. (2018) come to a similar result as Swarthout and colleagues. Critically reviewing the literature it reads on page 5307: "Recently, Duke et al. (2017) reported that, in a 2-year field study, they did not find consistent effects of glyphosate, the glyphosate-resistance transgene, or field crop history on measured mineral content of leaves or harvested seed of GR soybean. Applying in total $1.74 \mathrm{~kg}$ a.e./ha per season, effects on minerals were reported to be small and inconsistent between years, treatments, and mineral and were thought to be random false positives."

Therefore, we don't see a disagreement here.

Chelating properties of glyphosate in the reevaluation process The letter to the editor can be read as critique of the statement in Mertens et al. (2018) "Although the chelating properties are well known, this potential additional environmental risk was never adequately considered in the regulatory risk assessment (EFSA 2015a, b)" because it defends EFSA's analysis (2015b) by citing two paragraphs of its conclusion:

(i) "33 articles draw conclusions on the interactions of glyphosate with micronutrients, nutrient uptake and metabolism. In particular, the ability of glyphosate to chelate micronutrients such as manganese, iron and phosphate and the resulting effects in plants are addressed" (page 3249) and

(ii) ..."the available scientific data suggest that the strong affinity of glyphosate and its metabolite AMPA to most soils prevents the uptake of these compounds by root systems of non-target plants" (page 37, Summary of observations on other undesirable or unintended sideeffects).

Mertens et al. $(2018,5311)$ quote the complete second paragraph which reads: "Findings have shown that glyphosate can be transferred from the roots of target plants to the rhizosphere and non-target plants can also be influenced (e.g. reduced absorption of micronutrients - Mn and Fe deficiency). Glyphosate is a strong chelator to various divalent cations such as $\mathrm{Ca}, \mathrm{Fe}, \mathrm{Cu}$ and Mn. Glyphosate binds micronutrients in the soil and can cause micronutrient deficiencies in plants that increase their susceptibility to disease, especially on soils with poor nutrient content. However, the available scientific data suggest that the strong affinity of glyphosate and its metabolite AMPA to most soils prevents the uptake of these compounds by root systems of non-target plants" (EFSA 2015b, page 37).

Both paragraphs (on pages 3249 and 37) are the only ones found in EFSA's final addendum to the Renewal Assessment Report (RAR) for Glyphosate (EFSA $2015 b)$ dealing with the chelating properties of glyphosate. They imply that EFSA addressed the issue of nutrient chelation by glyphosate thoroughly in its reevaluation. However, a closer look to the list of 129 articles in Section B.8.11.7 (EFSA 2015b, pages 3250-3366) does not support this implication. It reveals that (a) EFSA's "proposed action" with 113 of them was "Not to be considered as publication does not focus on an environmental fate-related end-point.", (b) 8 articles have not been considered for other reasons, and (c) only 8 articles have been considered as additional or supporting information. While EFSA leaves it open which articles belong to the group of 33 referred articles, there is reason to believe that hardly any of them have been considered by EFSA in the assessment of 
glyphosate. This is supported by the fact that the 8 considered articles in point (c) deal mainly with glyphosate degradation and fate in soils and integrated plant protection, two are reviews.

Mertens et al. (2018) state that

In the process of reevaluation of glyphosate, chelating properties of glyphosate have not been discussed widely. In its conclusions on the peer review of the risk assessment of glyphosate, EFSA (2015a) did not provide data on potential impacts of glyphosate on plant nutrient availability.

Therefore, we reject the putative critique and still conclude that this property of glyphosate has not been adequately addressed in the process of reevaluation of glyphosate.

\section{References}

Cakmak I, Yazici A, Tutus Y, Ozturk L (2009) Glyphosate reduced seed and leaf concentrations of calcium, manganese, magnesium, and iron in non-glyphosate resistant soybean. Eur J Agron 31(3):114 119. https://doi.org/10.1016/j.eja.2009.07.001

Duke SO, Rimando AM, Reddy KN, Cizdziel JV, Bellaloui N, Shaw DR, Williams MM, Maul JE (2017) Lack of transgene and glyphosate effects on yield and mineral and amino acid content of glyphosate-resistant soybean. Pest Manag Sci 74:1166-1173. https://doi.org/10.1002/ps.4625
EFSA (2015a) Conclusion on the peer review of the pesticide risk assessment of the active substance glyphosate. EFSA J 13(11):4302. https://doi.org/10.2903/j.efsa.2015.4302

EFSA (2015b) Final addendum to the renewal assessment report-public version. Risk assessment provided by the rapporteur Member State Germany and co-rapporteur Member State Slovakia for the active substance Glyphosate according to the procedure for the renewal of the inclusion of a second group of active substances in Annex I to Council Directive 91/414/EEC laid down in Commission regulation (EU) No. 1141/2010. 4302add public pdf http://registerofquestions.efsa. europa.eu/roqFrontend/outputLoader?output $=\mathrm{ON}-4302$

Eker S, Oztuk L, Yazici A, Erenoglu B, Römheld V, Cakmak I (2006) Foliar-applied glyphosate substantially reduced uptake and transport of iron and manganese in sunflower (Helianthus annuus) plants. J Agric Food Chem 54(26): 10019-10025

Harris WR, Sammons RD, Grabiak RC, Mehrsheikh A, Bleeke MS (2012) Computer simulation of the interactions of glyphosate with metal ions in phloem. J Agric Food Chem 60(24):6077$6087 \mathrm{http} / /$ pubs.acs.org/doi/full/10.1021/jf3004288

Mertens M, Höss S, Neumann G, Afzal J, Reichenbecher W (2018) Glyphosate, a chelating agent-relevant for ecological risk assessment? Environ Sci Pollut Res 25:5298-5317 https://link.springer. com/article/10.1007\%2Fs11356-017-1080-1

Swarthout JT, Bleeke MS, Vicini JL (2018) Comments for Mertens et al. (2018) Glyphosate, a chelating agent—relevant for ecological risk assessment?

Tesfamariam T, Bott S, Cakmak I, Römheld V, Neumann G (2009) Glyphosate in the rhizosphere - role of waiting times and different glyphosate binding forms in soils for phytotoxicity to non-target plants. Eur J Agron 31(3):126-132

Toy DF, Uhing EH (1964) Aminomethylenephosphinic acids, salts thereof, and process for their production. United States Patent Office, patent $3,160,632$ 